\title{
The Understanding of Environmental Citizenship among Malaysian Youths: A Study on Perception and Participation
}

\author{
Abdul Latiff Ahmad, Samsudin A. Rahim, Latiffah Pawanteh \& Fauziah Ahmad \\ Universiti Kebangsaan Malaysia, Malaysia \\ E-mail: alba@ukm.my, samsudinukm@gmail.com, latiffahpj@yahoo.com, zuhair@ukm.my
}

Received: February 24, 2012

Accepted: March 13, $2012 \quad$ Published: April 16, 2012

doi:10.5539/ass.v8n5p85

URL: http://dx.doi.org/10.5539/ass.v8n5p85

This project is funded by the Universiti Kebangsaan Malaysia under the research code: UKM-AP-CMNB-19-2009/1

\begin{abstract}
Over the past years, there have been great concerns over the global environmental issues. Human activities have contributed towards climate changes that are affecting the world. The rise of temperature has been noticeable and this strengthens the arguments of the greenhouse effect. Among the environmental concerns include carbon dioxide emissions by transportation, deforestation, open burning, excessive waste, river pollution and etc. These issues have raised the global need for environmental citizenship. It is a form of citizenship that prioritizes and emphasizes the importance of the environment and one that crosses the national territorial borders. It stresses the need to have citizens who inhibit greater awareness of the environment and try to maintain and preserve the earth by participating in 'green' activities and saving the earth. This research aimed at exploring the awareness, understanding, perception and participation of Malaysian youth with regards to environmental citizenship. Six focus groups were conducted within Klang Valley with each group comprising of 5-6 people. The informants consisted of Malay, Chinese and Indian youths between the age of 18-25. The questions were focused on the general and technical understanding of environmental issues, the sources of information on the environment and the role that these individuals and the community have played as environmental citizens.
\end{abstract}

Keywords: Enviromental, Citizenship, Malaysia, Perception, Participation

\section{Introduction}

Environmental issues have been of strong concern over the years. Global warming, climate change, greenhouse effect, pollutions, deforestation are some key words that describes the environmental issues and problems. Stamm, Clark and Eblacas (2002) highlights the importance of public understanding of the environment and have identifies it as a mass communication problem. The key message of the importance of environmental issue has not been properly conveyed to the audience. And though some maybe aware of the implications of not preserving the environment, they do not feel the need to participate in ways of preserving and saving the environment.

With globalization, the task of co-operation between global citizens are further required. Hopefully, with the development of new and social media technology, the aim of creating awareness and increasing participation on environmental activities can be successful. With the issue of the environment being of a global concern and it involves issues of rights and duties towards the environment, the concept of environmental citizenship have since been established. It works on the parameter of the basic definition of citizenship but incorporates the growing concern over environmental issues.

\section{Environmental Citizenship}

The United Nations Environment Programme (UNEP) defines Environmental Citizenship as 'a simple reiteration of a known fact - that the preservation of the environment is an obligation entrusted upon everyone and all governments by virtue of the inherent relationship between people and nature and between citizens and their governments (UNEP, 2005). 
In the recent Rapid Research and Evidence Review conducted by the Sustainable Development Research Network, Dobson (2010:6) stated that environmental citizenship was referred to as "pro-environmental behavior, in public and in private, driven by a belief in fairness of the distribution of environmental goods, in participation and in the co-creation of sustainable policy. It is about the active participants of citizens in moving towards sustainability."

Both these definitions emphasize on the elements of pro-environmental behavior and the role and obligation (rights) of the individuals, the citizens towards sustainability.

Dobson (2010) further listed down six characteristics of an environmental citizen. The characteristics are 1) environmental sustainability is a common good and will not be achieved by one's self interest. 2) environmental motivations are not only private but public motivated. 3) believes the importance of ethics and moral knowledge. 4) the rights and duties are focused within the citizens 5) the responsibilities is not only towards people one knows but also towards those regarded as a distant stranger 6) believes that pro-environmental behavior can create positive impact.

For the purpose of this paper, all the various definitions are merged into a general understanding of the concept of environmental citizenship. The key essence is the issue of obligations of the citizens and the role that they can play in championing the issue of environment and how they can contribute towards obtaining a greater environment. It also combines activities done within the private or public spheres which can lead to sustainable development.

\section{Malaysia and Environmental Citizenship}

A study on environmental citizenship was conducted by WWF-Malaysia and Partners in 2007 exploring the emerging perspectives of the concept in Malaysia. The survey study found that relatively, only $45 \%$ of adults and students understood the causes of environmental problems. Between $52.7 \%$ to about $65.3 \%$ of the adults admitted that they have allocated their personal effort towards environmental activities. However well over $90 \%$ disapprove with the way the government and authorities handled the haze problem in Malaysia.

The interview portion highlighted important concerns over environmental issues in Malaysia. Among the concerns were the lack of environmental role models for Malaysians, the lack of commitment among Malaysians in participating in environmental activities and that need for a sense of ownership where Malaysians would take responsibility and preserve the environment.

Tamby Subhan Mohd Meera, Lilia Halim and Thiagarajan Nadesan (2010) studied the level of knowledge, attitude, skill and participation of Malaysian students in context of environmental citizenship. The research found that school students knowledge level of environmental issues were $35 \%$, their knowledge on the fauna and biodiversity was $20.3 \%$ and international environmental treaties $25 \%$. About $20.2 \%$ of students admitted that they mainly obtain information from the newspapers and televisions. The result indicated that the knowledge levels of students are still very low and there is a strong need for more environmental education among schools in Malaysia.

\section{Awareness, Understanding, Perception and Participation}

Schulitz and Oskamp (1996) stress the importance of knowledge, attitude, values and the practices of the people to be the key components towards a better quality environment. It is important for individuals to have the knowledge on what the environment is all about and the importance of it. Attitude reflects how individuals relate to the environment and it involves the issue of perception as to how the individuals view issues surrounding the environment. Participation focuses on how the individuals react to issues surrounding the environment. It indicates whether the individuals play an active role in trying to preserve the environment. It relates to issues on whether one recycle, or does one use the fabric bag, or the roles they play in conserving energy or whether they participate in being active 'green' club members.

Awareness and understanding are two relatable terminologies. Awareness comes before understanding. An individual may be aware of certain thing but they may not understand what the information is about. Understanding comes with knowledge, whether an individual knows about a certain issue. Results of a 2006 PEW Global Attitudes survey indicated that developed countries had greater awareness on issues related to global warming compared to developing countries. It further stated a majority of people in Nigeria, Indonesia and Pakistan have never even heard of global warming. Another highlighted element was that many in the Muslim world were not aware of global warming. Patchen (2006) described the importance of knowledge and attitude towards the environment and how it can be affected by personal characteristics and also through socialization. Being aware and understanding of a certain issue could lead to a perception being built. 
Jandt (2010) described how perception consist of three elements of structure, organize and interpret in contracting information. Leiserowitz (2007) studied the public perception of climate change and emphasized the importance of exploring public perception as it can create further impact towards the future development of policies relating to the environment. Schmidt (2007) analyzed the co-relation between the concern for the environment and how it translates into a form of action towards preserving the environment. She conducted a class on environmental issue and discovered that as students are more aware of environmental issues, they are more willing to participate in environmental activities such as recycling.

Under the Model of Responsible Behavior, Hines, Hungerford and Tomera (1986) identified variables that contributed towards forming pro-environmental behavior. They listed knowledge of issues and action strategies, the locus of control, attitudes, verbal commitments and the individual sense of responsibility as key elements towards achieving pro-environmental behavior. Thus, individuals must be aware and understand about environmental issues and know to deal with the situation. The individuals must also believe that he or she can make the difference. A positive attitude is also important and when a person mentions that plan for the environment, there are strong possibilities that they may behave in that way. And lastly, individuals must have that sense of responsibility and engage in pro-environmental activities.

Blake (1999) discusses about issues that may prevent individuals from taking up a pro-environmental behavior. He listed the importance of the relations between the individuals, society and the institutions. Blake listed three barriers which are individuality, responsibility and practicality. Individuality refers to the individuals take on environmental issues. They might not be interested or even lazy to find out. Responsibility looks at whether it has a direct effect on them. For example they do not trust certain people or authorities or they do not own any property which requires them to play a stronger role. Practicality may be due to a lack of time, or not being able to find recycling centers or even did not get enough information on the environmentally related activities.

This research aimed at exploring the understanding and awareness of environmental citizenship in Malaysia and also to view their perception and participation level on environmental activities.

\section{Methodology}

In exploring the key understandings of environmental citizenship, the focus group approach was used to gather information. The focus group was chosen due to its nature and process which is believed to have provided the researchers, the answers to the questions posed. The synergistic nature as described by Stewart and Shamdasi (1990) emphasized on the importance of group work and how this interaction will allow the researcher to obtain rich data and information. Kreuger and Casey (2000) argued how the focus group provided a natural setting of the real world in which an individual can be influenced by the people around them or be the actor of influencing others. It is able to explore the meanings, identities and the norms that is being experienced in the real world.

In retrospect, the researchers believed that in exploring the issue of environmental citizenship, the focus group approach would encourage the discussions and provide the data required.

\subsection{Informants}

Six focus groups were conducted around Klang Valley. Each focus group consisted of 5-6 people in a group. The selection criteria of the informants were that they are staying within Klang Valley and currently studying or have obtained higher level education (post Sijil Pelajaran Malaysia). The informants must also be between the ages of $18-25$.

\subsection{Group Interviews}

Each group had either a combination of male or female students or consists of only one gender. The six groups were also divided by their ethnicity where two groups consisted of Malay students, two groups of Chinese students and two groups of Indian students. The groups were mixed between the male and female students with the exception of the Indian student group. The reason the divisions were made is to minimize any discomfort among the respondents in sharing their point of views. This is to encourage a more relaxed environment where the students are able express themselves openly without feeling restrained.

A thematic approach was used in structuring the focus group questions. It acted as a guide in obtaining the key information from the informants. The interviews were conducted in various locations which included university classrooms, fast food restaurants and local cafes. The focus group interviews lasted between 50 minutes to one hour. The data were transcribed and organized as to the frame of analysis which had been documented to support the research questions stated. 


\subsection{Frame of Analysis}

For the purpose of this study, the data were organized under three headings. The three categories are the general and technical understanding of environmental issues, the source of information on the environment and the role that these individuals and the community have played as environmental citizens. The three categories were selected as it is best to reflect the main aim of this research which is to explore the understanding, awareness, perception and participation of the youth towards environmental citizenship. It is believed the first two categories will be able to provide arguments towards understanding, awareness and perception while the last category would reflect the participation level of the youth.

\section{Findings and Analysis}

The responses from the focus group discussions were divided into four key themes which consist of awareness, understanding, perception and participation. The informants were given a range of question. Among them were related to demographics, general understanding on the environment, sources of information on environment, the control of the environment and the role of the individuals and the community within environmental citizenship.

\subsection{Awareness}

Generally the informants were aware of the environmental issues or problems that are happening around them. They were able to cite examples indicating that they are aware of general environmental problems that are faced by the not only by the country, but also in a global scale. They knew the importance of saving earth and they gave a lot of examples with regards to the problems. The popular examples were pollution, air, water and some even quoted noise pollution. They are aware from their own personal experience either by reading newspaper, watching television or through travels, as one can even make a comparison between Malaysia and Singapore. The informants are aware of the problems and they knew that it is a problem.

To me, environmental issue is a bit different...for example, the cutting of trees, I have heard this from before but until today it's not finished, still not over - G2

If we look in Malaysia, by the side of the roads, there is a lot of rubbish. If we go to Singapore, we can't even find one rubbish by the roadside - G3

Ecosystem, like pollution. Like air pollution, water pollution.-G5

Environment issue like pollution, factory smoke, water pollution and noise pollution.-G5

Air pollution, water. Air pollution.. For example the smoke from the car. Smoke from factories. Water pollution.. for example toxic waste from factories, throwing of rubbish in the river - G6

\subsection{Understanding}

Under the section of technical understanding whether the informants knew of any scientific terms or could explain the environmental situation using specific terminology. Generally, the informants were able to identify with some key words such as Ozone layer, greenhouse effect, global warming, CFC and release of carbon dioxide. Among the most noticeable answers were related to the thinning of the ozone layer and the rise in global temperature. Though they are able to provide examples with the scientific terms, there is more for them to understand. They are aware of these words however it is only at a surface level. They are able to explain basic processes but not further. For example, the greenhouse effect understanding is merely about the rise of temperature and not about the details.

Yes. Caused by the thinning of the ozone layer...the sun...the sun ray becomes dangerous for the skin.G1

What we know is that the whole world, there is a problem with global warming la..The temperature is rising. $-G 2$

The greenhouse, it uses the gas that is within our atmosphere, when this gas.. When the sunray..It will go into the earth's atmosphere and get trapped. The temperature will rise.-G2

Air pollution like the usage of a lot of vehicles that releases carbon dioxide. So this well pollute the air and also usage of CFC in aircond or something..G3

In my opinion, the increase in carbon dioxide gas will make it more hot la. Like last time, when we were kids, we will go to the field and play. Even if it's really hot, we will go and play. Now, even like to cross the road, Oh my goodness it is so bloody hot like that..G4

The green house effect is the sudden rise of temperature..G5 
The oxygen getting lesser, tree getting lesser. The oxygen getting lesser because the tree getting lesser due to the rapid development. G6

The informants were also enquired whether they knew of any policies regarding the environment in Malaysia. Though there were some general answers given on cutting of trees, open burning and toxic waste, there were quite a number who are not aware of any law or policies regarding the environment in Malaysia. Some informants also admitted that they know there is a law however they do not know the specifics and what it relates to.

Emmm.. Acts that prohibit open burning - G1

Maybe its like do not throw rubbish, open burning...G4

I think I have come across throwing toxic waste will lead to two years imprisonment and fine.- G4

Laws with regards to the cutting of trees.-G5

I don't know..haha...-G2

To be honest, I don't really know anything about the law or policy - G3

I think that I have not heard yet but the thing is maybe there, don't know - G3

I don't know about any law, but I know there exist the law - G6

\subsection{Perception}

In looking at perception of the informants regarding the environmental issues, they do admit that the environment is an important subject matter and that there is a need to maintain and preserve it. However, there were negative perceptions as to the practice of maintaining a good environment, the facilities, execution of pro-environmental behavior with the execution and also the authorities involved. There were comments made with regards to the attitudes of Malaysians who though is aware of the importance of taking care of the environment, chose not to be bothered. There were also calls to increase the campaigns on saving the environment just to create greater awareness. The lack of facilities to recycle or even directions to recycling centers are also considered as a problem as people do not know recycling centers near their homes.

A strong comment was made against the system of action. Some of the informants felt that the local authorities were inefficient in handling environmental issues. They can make a report but they feel that it goes nowhere and it is not being dealt with in an efficient manner. Some even went to the extent of stating that there exists corruption within the system with law-breakers such as factory owners cutting deals with local authorities. None of them have admitted to experiencing the efficiencies themselves or witness any corruption taking place however that is the perception that they have surrounding this issue.

There is corruption ... ah between the local authorities and the factory owners. $-G 1$

I think it (the environment) is important. I think the Malaysians are ignorant a bit la. The consciousness is low. They have the knowledge, but we are like lazy to take action and do something - G2

I feel there is still few rubbish disposable places, the civic consciousness of the individuals, very few campaigns, campaigns on saving the environment - G3.

It's because the execution is not that strict. We have advertisements on radio, television and all. People still watch but next, maybe they won't continue what they suppose to do. Because they don't have fear on them, because no real action is taken - G3.

The release of toxic from factory, all big company, they do have......they are people who waste at river and all. But it doesn't come to the eye. It is being covered. G4

Interrelated...corruption and effect on the environment..G4

..and also if you do a report, it takes time for coming and need to keep on reminding them about the thing and what happening. They not efficient..G6

\subsection{Participation}

This section of the study discusses the participation of the informants in environmental activities. With the development of new media, the youth are now using new forms of social media such as YouTube, Facebook and Twitter to share information on the environment. Though they admitted that the main priority of using these media is not towards searching information for the environment, they have engaged in environmental activities through this medium. Among the most highlighted environmental activities that they obtained information from 
the Internet were Earth Hour and the Go Green Project. They admitted to obtaining information on these projects from Facebook first compared to other forms of media. Some even choose to forward the information to others. However, though they are able to share the information, there is still a problem if they do not practice pro-environmental behavior. For example, in the first year of Earth Hour campaign, many had practiced switching off their lights for one whole hour. However, the activities were no longer done in the following years due to a lack of publicity.

Schools have also played a strong role in educating pro-environmental behavior. Most admit that they have learned about the environment from the Science subjects. What was noticeable was that the Chinese and Indian youth had also indicated that they had learned a lot from Moral Education, a subject which is not taught to the Malay students in schools as they would be taking Islamic studies. It does raise the question on whether the Malay students are getting less exposure on environmental behavior in school.

Religion also plays a strong role among the student's environmental activities and students have admitted to having exposure to the care of the environment through participating in religious community activities such as gotong-royong (group clean-up activity), cleaning the beach, planting trees and collecting donations.

In secondary schools, there was moral education which had tasks on this issue....aaa..in university...student societies - G1

I went to YouTube, search 2012. The video said that earth will be destroyed...so..I posted in on Facebook.-G1.

On my own, I express in FB (Facebook), blog, twitter...effective la ... because of the community...G2

Like me..I recycle, I separate the bottles, I collect newspapers and if anyone's throws rubbish everywhere, I would advise them..I have set myself not to be like others.

I join Zero polystyrene group. So I invite my friends to join. I use media social, face book.-G 4

Earth hour. The first year I do. The next year, I didn't. no publicity in university. -G4

In my kampong, there is a Buddha society...they collect, so I donated to them..GI

I have gone to a camping trip organized by the schools Islamic society...near the beach..the activities were like jungle trekking and cleaning up the beach - G2

In the kampong, there is gotong-royong (group clean-up activity). Usually handled by the Mosque's qariah. Usually I would join la..if I see rubbish by the sides I will pick it up lah..G3

I joined Walk For Tree where we actually bring a tree each of us then give it to the community, neighbourhood. We ask them to plant it. It's under NGO, its religious one. Example like Sri Sathia Sai Baba organization. - G5

The next aspect looks at whether the youth would comment or advice others to take on a more pro-environmental behavior, the general answers were mainly negative. Among the comments made were on not meddling into other people's business. Though one is aware of the global impact of pollution, for example, one is still skeptical of telling others not to do open burning. A few of the informants stated that they may be more comfortable telling to people of their own ethnicity but not to others. They do not want to offend people and would like to maintain harmony within society. It looks as though that the youth knows that environmental problems is both a national and global concern, they still think about this matter at an individual or even small community mindset - such as preserving harmony within a kampong and not wanting to disrupt the ties. There are also those who chose to remain quiet and not do anything.

No, I don't think I'm brave enough..G1

I do not want to meddle.. G2

I will not say anything. However, to those who are the same ethnic, I will tell him...G3

I don't know what to do because I feel like I'm useless. I think the thing is like in the mindset of the people. If you look at pollution, they will not stop it. Just look at it.. G3

Certain citizen, you can see them make a report on television but we only look at it, we don't do anything.-G4

Like open burning when I go back to my kampong...I went and said " Auntie, you cannot do this, it's not good" and after that she looked at me and said "ala...I don't burn a lot, 
that's not much effect on environment."-G4

To be honest, we don't do anything.. G4

I have advise a person from another race, that person burned rubbish close to my house. G5

Maybe might offence(offend) them unintentionally...G1

\section{Discussions}

The findings above had shown that the general level of awareness and understanding among Malaysians on environmental issues are satisfactory. However the key component of being part of environmental citizenship is the practical aspect, where individuals are suppose to participate and practice the rights and duties towards a better environment. Concepts like recycling are familiar to the youths interviewed, however, the practice of it is still lacking. Reasons for not participating towards environmental activities include not bothered (though they understand the importance of it), not being able to change the world or make an impact since you are only an individual, not knowing where the closest recycling centers or other environmental activities are. This supports Blake's (1999) argument on individuality, responsibility and practicality when people are not bothered or interested to find out further. It could also be because they have lost the faith in the system which will be discussed later.

Though the general awareness and understanding are relatively satisfactory among the informants interviewed, the technical knowledge with references to processes and cause and effects within the subject matter of the environment is something that needs to be further developed. There is also a negative perception that is being built among the youths with regards to local authorities and the environment. They believe that there is a lack of authoritative power and even assumed corruption as a form of abuse of power. The informants felt that there is no point to report or complain about any activities as it will not be taken into action or the whole process is just inefficient. These negative perceptions are being built without the personal experience of the informants. It is solely based on hear says of other people within the community. This perception can be damaging on the reputation of the local authorities and thus they need to build the trust from the public. There must also be an in-depth as to why people form such perceptions.

There is a need to regain public confidence on the system or else the whole process will not work through. Individuals feel that they are unable to practice their rights if the authorities are not playing that role. Currently, awareness on policies are still very minimal thus they only know the basic right and wrong without understanding the full implications of it. There is a need to have stronger emphasis on creating awareness on this key issue.

Social ties within society are also another barrier to environmental citizenship. Individuals feel that by telling or advising others, they are meddling into other people's business and might even disrupt social harmony. A few respondents admitted not willing to advise people of other ethnicity, because of the reasons stated above.

Schools have played a strong part in educating the youth about issues on the environment. Aside from just the classroom activities, clubs and societies have also educated the students with the establishments of Kelab Alam Sekitar and Kelab Pencinta Alam. Religion has also been a strong point with students learning about their environmental activities through activities organized by these religious bodies. This is a different platform from students as religious activities are usually activities within the communities and are usually organized informally. Today with the new media and technology, individuals are able to share information on the environment, especially through Facebook, Twitter and YouTube. Environmental activities such as Earth Hour have used the social media extensively in sharing information. Most informants had also stated that social media has played a prominent role in them learning about environmental activities. However, the exposure that they have received are not really being put into practice and in the end it just ends there with not many people taking up this issue seriously.

\section{Conclusion}

Though Stamm et al. (2002) have stated that environmental problems is a mass communication problem, this study has indicated that it is more than just a mass communication issue. Generally, the youth of Malaysia are aware of the environmental problems faced in the world and though the technical understanding can be improved, the general understanding of the state of the earth and what can be done to preserve it is satisfactory. However, individuals are still not taking on that active role and participate in activities that would unite environmental citizens. Yes, they do agree of the importance of having a good environment but they are not taking that extra step, as an active environmental citizen, to do their part in saving earth. Environmental educational programs should be continued on in schools, campaigns should also be continuous as this will keep on reminding people of 
their environmental rights and duties. The sad fact is that these youths are not practicing these rights and duties towards a good earth, towards a good home.

\section{References}

Arnold, H. E., Cohen, F. G., \& Warner, A. (2009). Youth and Environmental Action: perspectives of young environmental leaders on their formatice influences. The Journal of Environmental Education, 40(3), 27-36. http://dx.doi.org/10.3200/JOEE.40.3.27-36

Ashley, M. (2000). Behaviour change and environmental citizenship: a case for spiritual development. International Journal of Children's Spirituality, 5(2), 131-145. http://dx.doi.org/10.1080/713670914

Bell, D. R. (2005). Liberal Environmental Citizenship. Environmental Politics, 14(2), 179-194. http://dx.doi.org/10.1080/09644010500054863

Blake, J. (1999). Overcoming the value-action gap in environmental policy: tensions between national policy and local experience. Local Environment, 4(3), 257-278. http://dx.doi.org/10.1080/13549839908725599

Bloor, M., Frankland, J., Thomas, M., \& Robson, K. (2001). Focus groups in social research. London: Sage Publications.

Dobson, A. (2003). Citizenship and the Environment. Oxford: Oxford University Press. http://dx.doi.org/10.1093/0199258449.001.0001

Dobson, A. (Ed.). (2010). Environmental Citizenship and Pro-environmental behavior: The Sustainable Research Network.

Dobson, A., \& Saiz, A. V. (Eds.). (2006). Citizenship, Environment, Economy. London: Routledge Taylor \& Francis Group.

Hasan, Z., \& Akhter, S. (2011). Determinants of public awareness and attitudes on climate change in urban Bangladesh: Dhaka as a case. European Journal of Social Sciences, 21(1).

Hines, J., \& Hungerford, H. (1986). Analysis and synthesisof research on responsible pro-environmental behavior: a meta-analysis. The Journal of Environmental Education, 25(1), 34-42.

Huckle, J. (Ed.). (2008). Sustainable development. London: Sage.

Kollmuss, A., \& Agyeman, J. (2002). Mind the gap: Why do people act environmentally and what are the barriers to pro-environmental behavior? Environmental Education Research, 8(3), 239-260. http://dx.doi.org/10.1080/13504620220145401

Leiserowitz, A. (2007). Human Development Report 2007/2008: Fighting climate change: Human solidarity in a dividend world. UNDP.

Marshall, T. H. (Ed.). (2009). Citizenship and Social Class. New York: W. Norton \& Co.

Meerah, T. S. M., Halim, L., \& Nadesan, T. (2010). Environmental Citizenship: What level of knowledge, attitude, skill and participation the students own? Procedia: Social and Behavioral Sciences, 2, 5715-5719.

Patchen, M. (2006). Public attitudes and behavior about climate change: what shapes them and how to influence them. Indiana: University of Purdue.

Pew Global Attitudes Project: No global warming warming alarm in the US. (2006). Washington D.C: The Pew Research Center for the People and Press.

Ritchie, J., \& Lewis, J. (Eds.). (2003). Qualitative research practice: A guide for social science students and researchers. London: Sage Publications.

Said, A. M., Ahmadun, F., Paim, L. H., \& Masud, J. (2003). Environmental concerns, knowledge and practice gap among Malaysian teachers. International Journal of Sustainability in Higher Education, 4(4). http://dx.doi.org/10.1108/14676370310497534

Scerri, A. (2009). Paradoxes of increased individuation and public awareness of environmental issues. Environmental Politics, 18(4), 467-485. http://dx.doi.org/10.1080/09644010903007344

Stamm, K., Clark, F., \& Eblacas, P. (2000). Mass communication and public understanding of environmental problems: the case of global warming. Public Understand, Sci., 9, 219-237. http://dx.doi.org/10.1088/0963-6625/9/3/302 